This is an Open Access article licensed under the terms of the Creative Commons

\title{
Torsion of Meckel's Diverticulum in a Child
}

\author{
Satoko Nose ${ }^{a} \quad$ Hiroomi Okuyama $^{a}$ Takashi Sasaki $^{\mathrm{a}}$ \\ Mika Nishimura ${ }^{b}$ \\ Departments of ${ }^{a}$ Pediatric Surgery and ${ }^{b}$ Pediatrics, Hyogo College of Medicine, \\ Nishinomiya, Japan
}

\section{Key Words}

Meckel's diverticulum · Acute abdomen · Bowel obstruction · Emergency surgery

\begin{abstract}
Meckel's diverticulum (MD) is a common congenital anomaly of the gastrointestinal tract, the majority of cases of which are clinically silent. Patients with asymptomatic MD can unexpectedly develop acute abdominal pain. Making a diagnosis of MD is often difficult due to the lack of specific symptoms caused by this condition. Diagnostic laparotomy can be useful for making an accurate and prompt diagnosis of complicated MD. We herein describe a pediatric case of torsion of a MD in whom we performed laparoscopic-assisted emergency surgery. The patient was an 11-year-old male who developed sudden severe right lower abdominal pain. Clinical and laboratory findings were suggestive of appendicitis, however computed tomography scans showed a large cystic mass in the pelvis. Exploratory laparoscopy led to a diagnosis of torsion of a MD, and wedge resection of the gangrenous MD was performed through an umbilical port incision. The patient's postoperative course was uneventful. We conclude that diagnostic laparoscopy followed by laparoscopy-assisted Meckel's diverticulectomy via an umbilical incision is useful in the treatment of acute abdomen caused by MD.
\end{abstract}

\section{Introduction}

Meckel's diverticulum (MD) is a true diverticulum that develops from the incomplete obliteration of the omphalomesenteric duct during embryonic development. MD generally remains asymptomatic, and complications are reported in only $2-3 \%$ of cases [1]. The common complications caused by MD include hemorrhage associated with peptic ulceration from heterotopic gastric mucosa located within the diverticulum and intestinal obstruction due to banding, volvulus, intussusception, herniation or tumor formation $[2,3]$. On the other hand torsion, particularly axial torsion, of a MD is an 
extremely rare complication [4-6]. Axial twisting around the narrow base easily causes necrosis and perforation of a MD [6].

Making a preoperative diagnosis of complicated MD is difficult because the symptoms can mimic a variety of more common ailments such as appendicitis. It is pivotal to make a prompt and accurate diagnosis when faced with complicated MD, which is often serious and necessitates aggressive surgical treatment. The use of diagnostic laparoscopy allows for both making an accurate diagnosis and developing therapeutic strategies in patients with acute abdominal pain. Compared with exploratory laparotomy, laparoscopic and laparoscopy-assisted open procedures are less invasive and deliver greater cosmetic benefits.

We herein describe a pediatric case of axial torsion of a MD, a rare complication, particularly in children. We successfully performed emergency diagnostic and therapeutic laparoscopy.

\section{Case Report}

An 11-year-old male presented with a 5-hour history of right lower quadrant abdominal pain and several episodes of bilious vomiting. The abdominal pain was initially colicky in nature. The patient denied any fever. Medical history was notable for one prior discrete episode of abdominal pain in a similar location 1 year previously that had resolved spontaneously. Physical examination revealed mild abdominal distension with guarding and tenderness. The patient's bowel sounds were audible. Laboratory tests revealed an elevated white blood cell count of $15,520 / \mu \mathrm{l}$ with $89.5 \%$ neutrophils. Plain supine abdominal radiography revealed dilated small bowel loops. Further evaluation with computed tomography (CT) scans showed localized bowel dilation, a $62 \times 43 \mathrm{~mm}$ cystic mass and some ascites (fig. 1). Under a diagnosis of bowel volvulus, exploratory laparoscopy was performed immediately. Laparoscopy revealed that the patient's peritoneal cavity was filled with bloody fluid and that a black, axially torsed, gangrenous MD, measuring $6 \mathrm{~cm}$ in length with a $2 \mathrm{~cm}$ base, was located $70 \mathrm{~cm}$ proximal to the end of the ileum ( $\underline{\mathrm{fig} .2}$ ). An additional $2 \mathrm{~cm}$ skin incision was made at the umbilical port and the fluid in the MD was aspirated, which allowed the MD to be pulled out through the umbilical incision. The MD was untwisted and wedge resection was performed (fig. 3). Histological findings confirmed the MD to be gangrenous with ectopic gastric mucosa. The postoperative course was uneventful and the patientwas discharged on the 7th postoperative day.

\section{Discussion}

MD is congenital and occurs in approximately $2 \%$ of the general population. In the majority of cases, MD remains asymptomatic. In all age groups, there is only a $4-6 \%$ overall lifetime risk of developing complications that require surgery $[7,8]$. Despite advances in radiologic techniques, MD remains difficult to diagnose and preoperative diagnoses are reported in $4 \%$ of cases [1]. Therefore, surgery tends to be delayed in cases of MD because of insignificant presentation in laboratory tests or on CT scans.

Torsion of a MD is a rare complication. The subsequent development of gangrene in a twisted MD is also reported to be extremely rare [6]. We conducted a systematic literature search that consisted of searching the PubMed database for the key words 'torsion' and 'Meckel's diverticulum'. Relevant original articles of case studies published in the English language were selected. Only 6 cases in children and less than 20 cases in adults were found. In most of these cases the preoperative diagnosis was acute appendicitis. Laparoscopy, used in 4 cases including 1 pediatric case, was reported to 
be helpful for both diagnosis and treatment $[9,10]$. The preoperative diagnosis was appendicitis with or without perforation in 5 of 6 reported pediatric cases [6, 11-15]. The fact that the mean time from onset of pain to surgery was 2.2 days in a literature review of pediatric cases indicates that making a preoperative diagnosis remains challenging. The mean size of MD in the reported pediatric cases was $5 \mathrm{~cm}$ in diameter with a narrow base [6].

The mechanisms underlying isolated torsion without involvement of the ileum, as seen in our case, remain elusive. It has been reported that twisting of MD occurs around the diverticulum's base, which is relatively narrow compared to the length of a giant diverticulum [2]. Although making a preoperative diagnosis of MD complications is challenging, minimally invasive methods can be used for treatment [9]. In our case, the use of diagnostic laparoscopy allowed us to make an accurate diagnosis of MD. The diverticulum was delivered via a slightly extended umbilical wound and diverticulectomy was performed extracorporeally. This method is a safe and minimally invasive technique used to treat complicated cases of MD. Diagnostic laparoscopy is also useful to avoid delayed surgery carrying substantial risks.

In conclusion, a very rare form of acute abdominal pain caused by a torsed gangrenous MD was found in the present case. The correct diagnosis of MD was made using exploratory laparoscopy in an emergent setting. Performing early surgery using diagnostic laparoscopy can help prevent significant morbidity and mortality in patients with complicated bowel pain of unclear etiology.

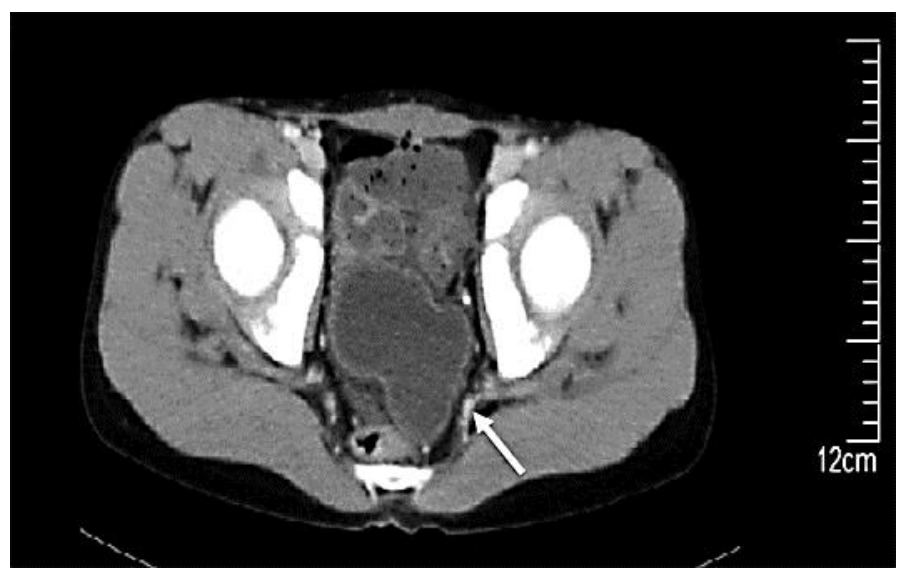

Fig. 1. Axial image from the contrast-enhanced CT scan. A gourd-shaped, fluid-filled structure with thickened wall (arrow) was located posterior to the bladder. 


\begin{tabular}{r|l|l|l}
$\begin{array}{r}\text { Case Reports in } \\
\text { Gastroenterology }\end{array}$ & $\begin{array}{l}\text { Case Rep Gastroenterol 2013;7:14-18 } \\
\text { DOI: 10.1159/000346313 }\end{array}$ & $\begin{array}{l}\text { Published online: } \\
\text { January 3, 2013 }\end{array}$ & $\begin{array}{l}\text { @ 2013 S. Karger AG, Basel } \\
\text { ISSN 1662-0631 } \\
\text { www.karger.com/crg }\end{array}$ \\
\hline
\end{tabular}

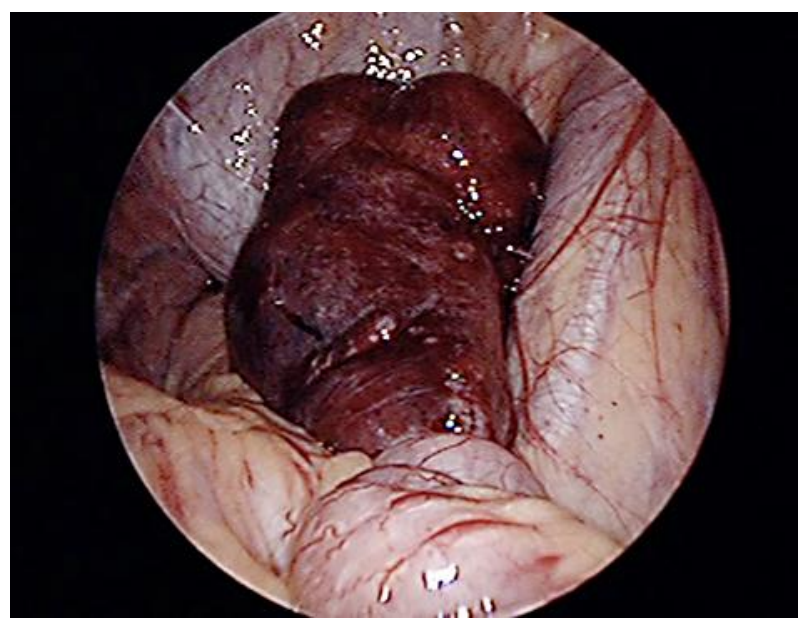

Fig. 2. Diagnostic laparoscopy revealed a twisted, dark-colored MD in the pelvis.

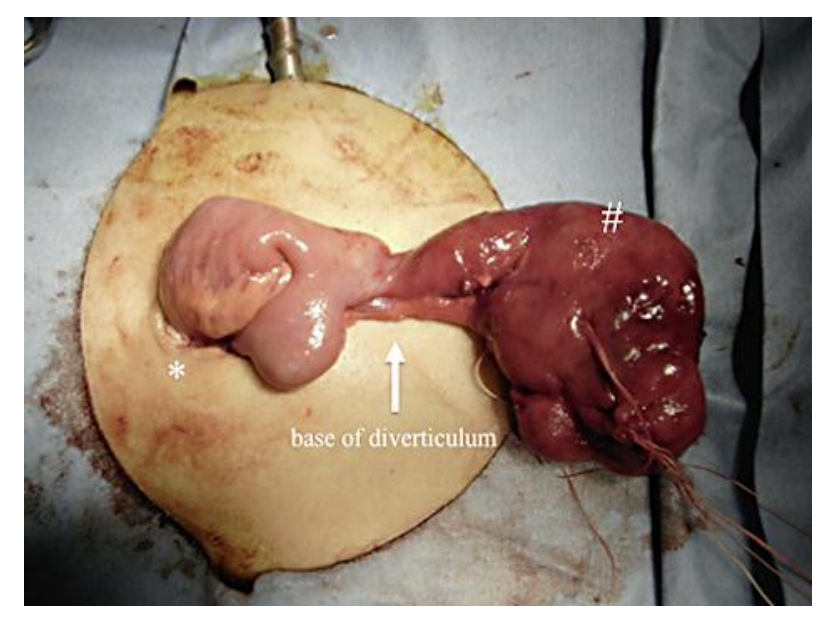

Fig. 3. The giant gangrenous MD (hash) was exteriorized and untwisted extracorporeally via the umbilical incision (asterisk).

\section{References}

1 Ludtke FE, Mende V, Kohler H, Lepsien G: Incidence and frequency or complications and management of Meckel's diverticulum. Surg Gynecol Obstet 1989;169:537-542.

$\checkmark 2$ Malhotra S, Roth DA, Gouge TH, Hofstetter SR, Sidhu G, Newman E: Gangrene of Meckel's diverticulum secondary to axial torsion: a rare complication. Am J Gastroenterol 1998;93:1373-1375.

3 Mackey WC, Dineen P: A fifty year experience with Meckel's diverticulum. Surg Gynecol Obstet 1983;156:56-64.

-4 Eser M, Oncel M, Kurt N: Gangrene secondary to axial torsion in a patient with Meckel's diverticulum. Int Surg 2002;87:104-106.

5 Tan YM, Zheng ZX: Recurrent torsion of a giant Meckel's diverticulum. Dig Dis Sci 2005;50:1285-1287.

6 Limas C, Seretis K, Soultanidis C, Anagnostoulis S: Axial torsion and gangrene of a giant Meckel's diverticulum. J Gastrointest Liver Dis 2006;15:67-68. 
7 St-Vil D, Brandt ML, Panic S, Bensoussan AL, Blanchard H: Meckel's diverticulum in children: a 20-year review. J Pediatr Surg 1991;26:1289-1292.

-8 Cullen JJ, Kelly KA, Moir CR, Hodge DO, Zinsmeister AR, Melton LJ 3rd: Surgical management of Meckel's diverticulum. An epidemiologic, population-based study. Ann Surg 1994;220:564-568; discussion 568-569.

9 Chan KW, Lee KH, Mou JW, Cheung ST, Tam YH: Laparoscopic management of complicated Meckel's diverticulum in children: a 10-year review. Surg Endosc 2008;22:1509-1512.

10 Shalaby RY, Soliman SM, Fawy M, Samaha A: Laparoscopic management of Meckel's diverticulum in children. J Pediatr Surg 2005;40:562-567.

11 Prasad TR, Chui CH, Jacobsen AS: Laparoscopic resection of an axially torted Meckel's diverticulum in a 13-year-old. J Laparoendosc Adv Surg Tech A 2006;16:425-427.

12 Farris SL, Fernbach SK: Axial torsion of Meckel's diverticulum presenting as a pelvic mass. Pediatr Radiol 2001;31:886-888.

13 Gallego-Herrero C, del Pozo-Garcia G, Marin-Rodriguez C, Ibarrola de Andres C: Torsion of a Meckel's diverticulum: sonographic findings. Pediatr Radiol 1998;28:599-601.

14 Larson J, Ellinger D: Sonographic findings in torsion of a Meckel diverticulum. AJR Am J Roentgenol 1989;152:1130.

15 Weekly clinicopathological exercise: torsion and gangrene of Meckel's diverticulum. N Engl J Med 1952;246:985-987. 